\title{
DESIGNING A MAP OF CLASSIFIED LEARNING ACTIVITIES FOR THE CUSTOMISED DEVELOPMENT OF TRANSVERSAL COMPETENCES
}

\author{
Andrés Boza, Marta Fernández-Diego, Mariluz Gordo, Leonor Ruiz \\ Universitat Politècnica de València, School of Informatics (SPAIN)
}

\begin{abstract}
The proposal for innovation and educational improvement presented in this paper focuses on identifying and classifying learning activities at different levels in order to reinforce those aspects required for an adequate coverage of the competence. The experience gained from the implementation in the classroom of the work developed in previous projects has revealed that each learning activity covers certain levels of competence. Even the same activity that is conducted in different courses should be classified into different levels. The overall aim to be covered includes the design of the scale to identify levels for the scope of the competence, and the identification and classification of activities according to the scale established to build the map of activities. The design of the map of classified learning activities enables: i) To have a broad vision of the activities carried out for the development of the competence. ii) To identify overlaps of activities at the same level, which raises the question of whether or not to eliminate any of the activities. iii) To identify levels not addressed by any activity, which encourages the development of activities that cover levels not reached by other activities. iv)To offer the students the map of activities as a tool for their training.
\end{abstract}

Keywords: learning activities, transversal competences, map of activities.

\section{INTRODUCTION}

The creation of the European Higher Education Area has brought about many changes. The most important is related to learning activities, which are considered seriously and in depth. In other words, the student will learn some contents at a certain level through a number of actions or tasks. According to Penzo et al. [1], learning-based teaching can be defined as the teaching organization based on learning activities.

While Higher Education plays an important role in providing competencies for innovation [2], the challenge is to develop a variety of innovation skills simultaneously. Learning experiences focused on the demands of life and work in the 21st century are needed because "we are currently preparing students for jobs that do not yet exist, to use technologies that have not yet been invented, and to solve problems that we do not even know yet"[3] .

The emphasis on the teaching and learning of Higher Education is growing worldwide, along with the recognition that innovation, growth and social progress in the future require skilled people. At the international level, the OECD's Innovation Strategy, launched in 2010, highlights the essential role of different competences in innovation processes. The European Commission [4] also promotes transversal key competences for all citizens and advocates that European cooperation in education and training should include somehow creativity, innovation and entrepreneurship at all levels of education.

The current trend in Higher Education is to improve the creativity and individual thinking of students in order to bring them closer to the world and the complex problems they will encounter. The UPV has undergone a process of adaptation to the requirements of the European Higher Education Area. The School of Informatics has adopted new teaching methods that promote a more active, practical and critical learning process. The UPV undergraduate and master's degree studies have a structure based on courses and disciplines. A discipline may include several courses. The dimensions of UPV competence aim to synthesize the profile of competences acquired by UPV students, ensuring the regulatory framework and recommendations in undergraduate and master's degree studies [5] [6].

The UPV has defined a total of 13 transversal competences: CT1-Comprehension and Integration; CT2-Application of Practical Thinking; CT3-Analysis and Problem-Solving; CT4-Innovation, Creativity and Entrepreneurship; CT5-Design and Project; CT6-Teamwork and Leadership; CT7-Ethical and Professional Responsibility; CT8-Effective Communication; CT-9-Critical Thinking; CT10-Awareness 
of Contemporary Problems; CT11-Lifelong Learning; CT12-Planning and Time Management; CT13Specific Instrumentation [7].

Following this approach, the authors of this paper participated in the educational innovation project called DAICE - Design of activities for the Innovation, Creativity and Entrepreneurship Competence in degree and master's degree. The project consisted of designing activities for the acquisition of learning outcomes associated with transversal competence CT4-Innovation, Creativity and Entrepreneurship. It should be noted that a learning outcome can be acquired through one or more activities and the same activity can contribute to the acquisition of one or more learning outcomes. The good practices proposed throughout the project included the following information: learning outcomes to be achieved, degree, level and course, contents to be covered, name or type of activity, description of the activity, assessment, time spent and resources used. All this facilitates their adaptation to other courses [8]. Thus, the activities identified as suitable may be applied by teachers in the classroom as tools to promote the acquisition of the competence by students.

The experience gained from the implementation in the classroom of the work developed in the previous project has revealed that each learning activity covers certain levels of competence. Even the same activity that is conducted in different courses should be classified into different levels. The proposal for innovation and educational improvement presented in this paper focuses on identifying and classifying learning activities at different levels in order to reinforce those aspects required for an adequate coverage of the competence.

The paper is structured as follow: Section 2 shows the objectives of this proposal. Section 3 describes the steps for designing a map of classified learning activities. And in section 4 the main conclusions are presented.

\section{OBJECTIVES}

The overall aim is to identify the set of learning activities that improve the adequate coverage of the competence.

More specifically, the aims to be covered are:

1 Design of the scale to identify levels for the coverage of the competence;

2 Identification and classification of activities according to the scale established to build the map of activities;

3 Complete the map of activities to cover non-covered ranges by designing new activities.

\section{DESIGNING A MAP OF CLASSIFIED LEARNING ACTIVITIES}

\subsection{Design of the scale}

The design of the scale is justified by the requirement to measure the level at which the learning activity contributes to the coverage of the competence. Measurement means assigning numbers, symbols or values to the properties of objects or events according to specific rules [9]. In social sciences, researchers work with abstract concepts that cannot be characterized as objects or events. In this field measurement can be defined as the process of linking abstract concepts with empirical indicators, which is carried out by means of an explicit and organized plan to classify (and often quantify) the available data (the indicators), in terms of the concept that the researcher has in mind [10], in our case the transversal competence. According to Grinnel and Unrau [11] the function of measurement is to match the "real world" with the "conceptual world". The first provides empirical evidences while the second provides theoretical models to understand that segment of the real world we are trying to describe.

The data measuring instrument plays a central role in this process. Without it there are no classified observations. Thus, the measuring instrument records represent visible values of abstract concepts. Although there is no perfect measurement, the idea is to get as close as possible to a faithful representation of the variables to be observed using the measuring instrument [11]. 
There are three basic issues regarding the variables to be considered when constructing an instrument [12]: operationalization, codification and the establishment of measurement levels:

1 The technical term "operationalization of variables" is used in research to designate the process by which the variable is transformed from abstract concepts to concrete, observable and measurable terms, i. e., dimensions and indicators [13]. This process includes the stages of nominal and conceptual definition of the variable, the dimensionalization of the variable (determining its factors, dimensions or components), defining indicators for the dimensions and finally identifying, developing or generating items or values for each indicator.

2 Data encoding means assigning to the data a numeric value or symbol that represents it. In other words, numeric values or signs that have a meaning are assigned to the different categories (response options) of each item or variable. For example, the Male - Female category can be coded as $1-2$, or the item "In this company I am free to make decisions" can be coded as 5) I totally agree; 4) All right; 3). Neither agree nor disagree; 2) Disagree; 1) Strongly disagree.

3 The best-known measurement levels are: (i) Nominal measurement level, where there are two or more categories of the item or variable, and there is no intrinsic ordering or hierarchy to the categories (e. g. gender is a categorical variable having two categories: male and female); (ii) Ordinal measurement level, where there are several categories that maintain a clear higher to lower ordering (e. g. president is more than vice-president, and in turn, more than general manager, but it is not possible to specify how much more); (iii) Interval measurement level. In addition to the ordering or hierarchy between categories, equal interchanges are established in the measurement, i. e., the distances between categories are the same across the entire scale (e. g. the variable of the number of employees in charge).

In the case of transversal competences, the scale design is a complex process that depends on the approach of the teacher (as designer of the scale) concerning the analysis of the transversal competence and on the nature of the competence itself. For example, the transversal competence "Lifelong Learning" has very different dimensions from the competence "Effective Communication", both because of the intrinsic characteristics of the competences and because of the subjective concerns of the teacher when defining dimensions and indicators.

An example of the process previously presented is the case of the UPV transversal competence "Innovation, Creativity and Entrepreneurship" where competition is approached as a process. Specifically, taking the descriptors of the definitions of innovation, creativity and entrepreneurship , the competence is defined as a process to be followed, it contains the following steps [8] :

1 Environmental analysis (opportunities);

2 Proposal of creative ideas (generate ideas);

3 Deployment (execution);

4 Risk and benefit assessment (added value).

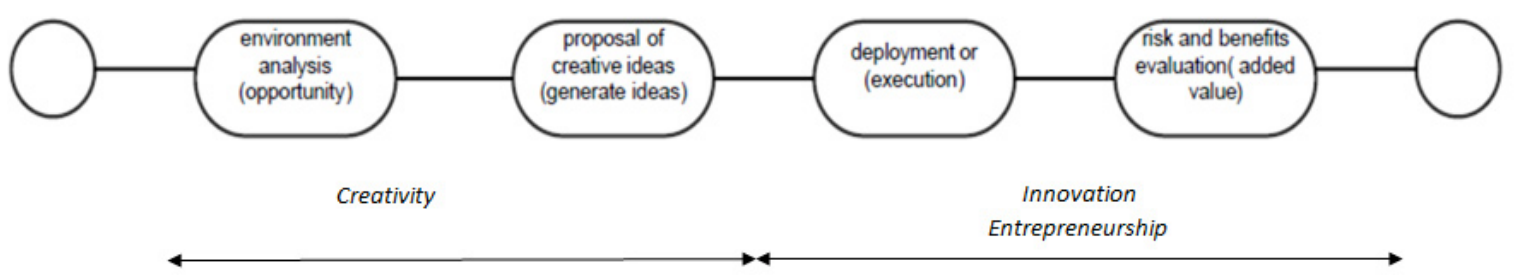

Figure 1: Process related to the competence of Innovation, Creativity and Entrepreneurship [8].

Thus, the operationalization of the competence in dimensions, indicators and items is presented in the following table: 
Table 1. Operationalization of the competence of Innovation, Creativity and Entrepreneurship.

\begin{tabular}{|c|c|c|c|}
\hline Variable & Dimension & Indicator & Item \\
\hline \multirow{4}{*}{$\begin{array}{l}\text { Transversal Competence } \\
\text { of Innovation, Creativity } \\
\text { and Entrepreneurship }\end{array}$} & $\begin{array}{l}\text { Environmental analysis } \\
\text { (opportunities) }\end{array}$ & $\begin{array}{l}\text { The student questions } \\
\text { reality. }\end{array}$ & \multirow{4}{*}{$\begin{array}{l}\text { Categories: } \\
\text { D. Not achieved } \\
\text { C. Under } \\
\text { development } \\
\text { B. Good / suitable } \\
\text { A. Excellent / } \\
\text { exemplary }\end{array}$} \\
\hline & $\begin{array}{l}\text { Proposal of creative ideas } \\
\text { (generate ideas) }\end{array}$ & $\begin{array}{l}\text { The student contributes } \\
\text { ideas. }\end{array}$ & \\
\hline & Implementation (execution) & $\begin{array}{l}\text { The student formally } \\
\text { shapes the ideas. }\end{array}$ & \\
\hline & $\begin{array}{l}\text { Risk and benefit } \\
\text { assessment (added value) }\end{array}$ & $\begin{array}{l}\text { The student identifies } \\
\text { results. }\end{array}$ & \\
\hline
\end{tabular}

The above table presents only one example since, as indicated previously, the designers of each scale are conditioned by the nature of each transversal competence and their own perspective. Thus, other scales may require measurements from 0 to 10 , the use of Likert scales or semantic differentials (e. g. for effective communication: Speaks clearly - Speaks unclearly).

With regard to measurement levels, in the case of the design of a scale that allows the classification of learning activities, at least two levels are required. The approach followed by this proposal is to establish the levels as an orderly path for the achievement of the competence, so that the levels to be used are the ordinal measurement level or the interval measurement level. However, the nominal measurement level can also be used when the map focuses on the dimensions themselves and not so much on their evolution (e. g. "The activity addresses the following categories: Innovation / Creativity / Entrepreneurship").

\subsection{Identification and classification of activities}

Firstly, the map construction requires the identification of learning activities aimed at the acquisition of the transversal competence. The previously operationalization work carried out where dimensions of the competence were identified facilitates this work, since the activities should cover one or more of these dimensions. Furthermore, this work is much simpler when the learning activities have already been conducted in the course and we already have a set of identified learning activities. However, if it is not the case, this process will be somewhat longer.

Secondly, activities should be classified according to the scale established to construct the map of activities. That is, identify the level (or levels) for each learning activity in order to place all activities on the map according to the defined scale. Thus, it is easy to identify the most suitable activities for each level of the scale.

Figure 2 shows an example of the map using a range of competence acquisition from 0 to 10 . The map shows the set of learning activities designed for the competence as well as their location within the scale.

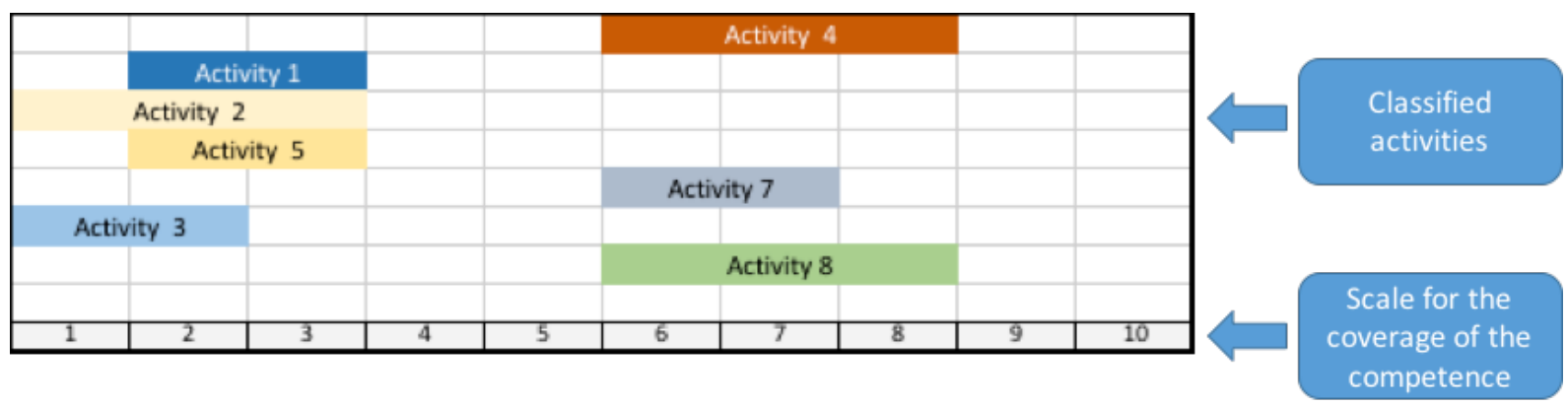

Figure 2: Map of classified learning activities for the customized development of transversal competences.

The location of the activities on the map allows: on the one hand, a) to identify sets of activities that are working at the same level, so it may not be necessary to deploy a whole set of activities in the classroom, since with the completion of one of these activities the students would have already 
covered the level (for example, level 2 is saturated with too many activities, activities 1, 2, 3 and 5). On the other hand, b) to identify levels not covered by any activity. Figure 3 shows these GAPs.

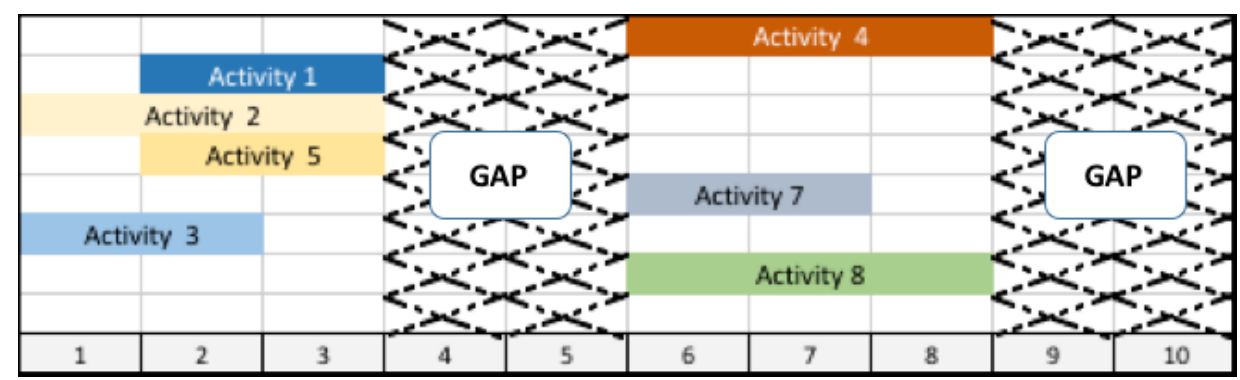

Figure 3: GAPs identified in the map of classified learning activities.

The fact of identifying these GAPs allows us to move on to the next stage in the configuration of the map of activities.

\subsection{Complete the map of activities by designing new activities}

The design of new activities to work on the transversal competence is facilitated by the construction of the map by following the previous stages, since it provides a guide for the identification of non-covered activities. In other words, the process of designing and analyzing learning activities is guided by the objective of filling the GAPs found. Figure 4 shows the inclusion of two new activities (activity 9 and $10)$ to cover these GAPs.

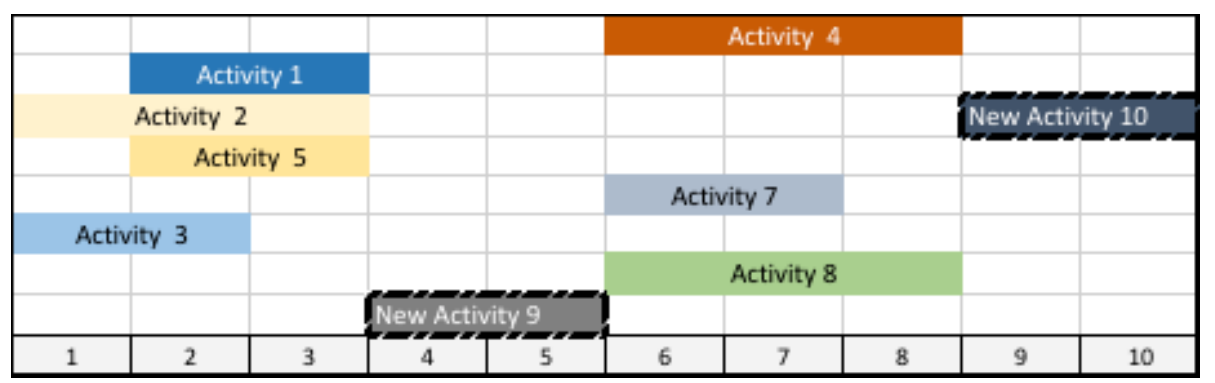

Figure 4: Incorporation of activities to cover GAPs.

\section{CONCLUSION}

This paper presents the steps to be followed in designing the map of classified learning activities for the customized development of transversal competences. Rather than focusing on a single transversal competence, this paper has approached the problem from a general perspective in order to be transferable to other transversal competences. Thus, as indicated above, on the one hand it will be necessary to adapt the work to the nature of the competence, and on the other hand measurement scales may be conditioned by the designer's approach regarding the competence. An example would be to use the map to identify activities according to their level of difficulty (e. g. activities for beginners, intermediate and advanced level activities) versus using the map to identify activities according to the contents addressed (e. g. for each of these categories: Innovation, Creativity and Entrepreneurship).

The design of the map of classified learning activities enables:

1 To have a broad vision of the activities carried out for the development of the competence.

2 To identify overlaps of activities at the same level, which raises the question of whether or not to eliminate any of the activities.

3 To identify levels not addressed by any activity, which encourages the development of activities that cover levels not reached by other activities.

4 To offer the students the map of activities as a tool for their training.

In this way, the map of activities becomes a tool for the students, where they can identify the activities by level and work to a greater extent on the most suitable ones according to their needs and potential. 


\section{ACKNOWLEDGEMENTS}

This research has been carried out within the framework of the project of innovation and educational improvement (PIME 2017-18 Ref. A10) funded by the Universitat Politècnica de València and the School of Informatics.

\section{REFERENCES}

[1] W. Penzo, V. Fernández, I. García, B. Gros, T. Pagès, M. Roca, A. Vallès, and P. Vendrell, "Guía para la elaboración de las actividades de aprendizaje," Cuadernos de docencia universitaria, vol. 15. Octaedro, pp. 1-67, 2010.

[2] European Commission, "Progress towards the common European objectives in education and training. Indicators and benchmarks 2010/2011," Commission staff working document. 2011.

[3] L. Darling-Hammond, "Introduction: Teaching and learning for understanding," Powerful Learn. What We Know About Teach. Understanding, Jossey-Bass San Fr. CA, pp. 1-9, 2008.

[4] European Commission, "New Skills for New Jobs: Action Now - A report by the Expert Group on New Skills for New Jobs prepared for the European Commission." 2010.

[5] A. Boza, L. Cuenca, M. Fernández-Diego, L. Ruiz, M. Gordo, F. Alarcón, M. M. E. Alemany, and R. Poler, "Innovation, creativity and entrepreneurship competence in higher education. Learning objectives and measurement," ICERI2014 Proc. Pages, pp. 405-411, 2014.

[6] M. Alemany, L. Cuenca, A. Boza, M. Fernández-Diego, L. Ruiz, F. Alarcón, and M. L. Gordo, "Innovation projects associated to the competence of innovation, creativity and entrepreneurship in the Universitat Politècnica de València," INTED2016 Proceedings. pp. 2903-2907, 2016.

[7] Universitat Politècnica de Valencia, "Competencias Transversales UPV." [Online]. Available: http://www.upv.es/contenidos/COMPTRAN/. [Accessed: 01-Jul-2017].

[8] A. Boza, M. Fernández-Diego, L. Ruiz, M. Gordo, M. M. E. Alemany, F. Alarcón, and L. Cuenca, "Transversal Competences as a Medium of Teaching. The Case of Creativity, Innovation and Entrepreneurship," in Strategic Innovative Marketing, Springer, 2017, pp. 3-10.

[9] S. S. Stevens, "Mathematics, measurement, and psychophysics," in Handbook of Experimental Psychology, no. 1, 1951, pp. 1-49.

[10] E. G. Carmines and R. A. Zeller, "Reliability and validity assessment," Quantitative Applications in the Social Sciences, vol. 17. p. 70 p., 1979.

[11] R. M. Grinnell Jr and Y. Unrau, Social work research and evaluation: Quantitative and qualitative approaches. Cengage Learning, 2005.

[12] R. Hernandez Sampieri, C. Fernandez Collado, and M. del P. Baptista Lucio, Metodología de la investigación. 2014.

[13] F. Arias, "El proyecto de investigación," Introducción a la metodología científica. 2006. 